\title{
In situ fabrication of Cu-bipy-BTC Metal-organic Framework Electrode for Catechol Detection
}

\author{
Zhipeng $L I^{l}$, Liwei $\operatorname{Ren}^{2, *}$ and Diannan $L u^{1, *}$ \\ ${ }^{1}$ Key Lab of Industrial Biocatalysis, Ministry of Education, China, Department of Chemical \\ Engineering, Tsinghua University, Beijing, China \\ ${ }^{2}$ College of Biological and Pharmaceutical Sciences, Three Gorges University, Yichang, Hubei \\ Province, China \\ *E-mail: ludiannan@tsinghua.edu.cn.com (D.L.); renliwei@ctgu.edu.cn (L.R.)
}

doi: $10.20964 / 2020.08 .52$

Received: 13 May 2020 / Accepted: 27 May 2020 / Published: 10 July 2020

In this work, the metal organic frameworks (MOFs) Cu-bipy-BTC $\left(\left[\mathrm{Cu}_{2}(\mathrm{OH})\left(2,2^{\prime} \text {-bipy }\right)_{2}(\mathrm{BTC})_{3}\right.\right.$ $\left.2 \mathrm{H}_{2} \mathrm{O}\right]_{\mathrm{n}}$ ) were in situ synthesized on the surface of a gold electrode directly to form a hybrid material of a $\mathrm{Cu}(\mathrm{OH})_{2}$ nanosheet and $\mathrm{Cu}$-bipy-BTC nanoparticle. The structure of this hybrid material on the electrode surface was characterized using Fourier-transform infrared spectroscopy, X-ray diffraction, scanning electron microscopy, and energy-dispersive spectrocopy. It is shown that the newly in situ synthesized Cu-bipy-BTC MOF can serve as active metal centers, and is embedded in different hydrophobic environments formed by $\mathrm{Cu}(\mathrm{OH})_{2}$ nanosheets. This unique structure is very similar to that of an active site of laccase, giving better catalytic activity. This MOF-based electrode enables the catalytic oxidation of catechol at $+0.4 \mathrm{~V}$ (versus $\mathrm{Ag} / \mathrm{AgCl}$ ). The amperometric responses are linear with concentrations of catechol ranging from 10 to $250 \mu \mathrm{M}$ and 250 to $1000 \mu \mathrm{M}$ with sensitivities of 1.6224 and $0.2591 \mu \mathrm{A} \cdot \mathrm{cm}^{-2} \cdot \mu \mathrm{M}^{-1}$, respectively. Compared with other catechol electrochemical sensors, this MOF-based electrode has advantages of higher sensitivity and easy manufacturability, facilitating its potential application in the detection of catechol.

Keywords: hybrid structure, asymmetry Cu-bipy-BTC MOF, $\mathrm{Cu}(\mathrm{OH})_{2}$ nanosheet, in situ fabrication, electro-catalysis, catechol detection

\section{$\underline{\text { FULL TEXT }}$}

(C) 2020 The Authors. Published by ESG (www.electrochemsci.org). This article is an open access article distributed under the terms and conditions of the Creative Commons Attribution license (http://creativecommons.org/licenses/by/4.0/). 